\title{
Optimization under uncertainty of thermal storage based flexible demand response with quantification of residential users' discomfort
}

\author{
Nicholas Good, Student Member, IEEE, Efthymios Karangelos, Member IEEE, Alejandro Navarro- \\ Espinosa, Student Member, IEEE, and Pierluigi Mancarella, Senior Member, IEEE
}

\begin{abstract}
This paper presents a two-stage stochastic programming model for provision of flexible demand response (DR) based on thermal energy storage in the form of hot water storage and/or storage in building material. Aggregated residential electro-thermal technologies (ETT), such as electric heat pumps and (micro-) combined heat and power, are modeled in a unified, non-technology specific way. Day-ahead optimization is carried out considering uncertainty in outdoor temperature, electricity and hot water consumption, dwelling occupancy, and imbalance prices. Building flexibility is exploited through 1) specification of a deadband around the set temperature, or 2) a price of thermal discomfort applied to deviations from the set temperature. A new expected thermal discomfort (ETD) metric is defined to quantify user discomfort. The efficacy of exploiting the flexibility of various residential ETT following the two approaches is analyzed. The utilization of the ETD metric to facilitate quantification of the expected total (energy and thermal discomfort) cost is also demonstrated. Such quantification may be useful in the determination of DR contracts set up by energy service companies. Case studies for a UK residential users' aggregation exemplify the model proposed and quantify possible cost reductions that are achievable under different flexibility scenarios.
\end{abstract}

Index Terms - Demand response, electric heat pump, combined heat and power, thermal energy storage, user comfort, energy service company.

\section{NOMENCLATURE}

\section{A. Acronyms}

ASHP Air Source Heat Pump

CHP Combined Heat and Power

DA Day Ahead

DHW Domestic Hot Water

DR Demand Response

ETD Expected Thermal Discomfort

ETDC Expected Thermal Discomfort Cost

EHP Electric Heat Pump

Nicholas Good is sponsored by E.ON New Build \& Technology. Alejandro Navarro-Espinosa is sponsored by Electricity North West.

Nicholas Good, Alejandro-Navarro Espinosa and Pierluigi Mancarella are with the School of Electrical and Electronic Engineering, University of Manchester, Manchester, M13 9PL, UK. (e-mail: \{nicholas.good, alejandro.navarroespinosa, p.mancarella\}@manchester.ac.uk).

Efthymios Karangelos is with the University of Liege, Liege 4000, Belgium (e-mail: e.karangelos@ulg.ac.be).
ESCo Energy Service Company

ETT Electro Thermal Technology

ICE Internal Combustion Engine

mu monetary unit

PDF Probability Density Function

SE Stirling Engine

SH Space Heating

TES Thermal Energy Store

\section{B. Indices}

$s \quad$ scenario index, from 1 to $N_{s}$

$i \quad$ time step index, from 0 to $N_{i}$

$b \quad$ dwelling index, from 1 to $N_{b}$

C. Parameters

1) Resource

$\tau_{b} \quad$ binary heater type indicator (1 for electricity con-

suming, 0 for electricity generating)

$P_{b}^{\min } \quad \min$ electrical power of unit $(\mathrm{kW})$

$P_{b}^{\max } \quad$ max electrical power of unit $(\mathrm{kW})$

$\rho_{s, i, b} \quad$ ratio of heater thermal output to electrical input

$\eta_{b} \quad$ combined heat and power unit electrical efficiency

$T_{i, b}^{\text {set }} \quad$ set temperature of dwelling $\left({ }^{\circ} \mathrm{C}\right)$

$\delta_{i, b}^{\text {low }} \quad \max$ down-variation from set temperature $\left({ }^{\circ} \mathrm{C}\right)$

$\delta_{i, b}^{\text {high }} \quad \max$ up-variation from set temperature $\left({ }^{\circ} \mathrm{C}\right)$

$R_{b} \quad$ thermal resistance of dwelling $\left({ }^{\circ} \mathrm{C} / \mathrm{kW}\right)$

$C_{b} \quad$ thermal capacitance of dwelling $\left(\mathrm{kWh} /{ }^{\circ} \mathrm{C}\right)$

$X_{b}^{\max } \quad \max$ temperature of TES $\left({ }^{\circ} \mathrm{C}\right)$

$X_{b}^{\min } \quad$ min temperature of TES $\left({ }^{\circ} \mathrm{C}\right)$

$R_{b}^{x} \quad$ thermal resistance of TES $\left({ }^{\circ} \mathrm{C} / \mathrm{kW}\right)$

$C_{b}^{x} \quad$ thermal capacitance of TES $\left(\mathrm{kWh} /{ }^{\circ} \mathrm{C}\right)$

2) Consumer Energy/Occupancy Scenario Profiles

$L_{s, i, b}^{D H W} \quad$ domestic hot water load (kWh)

$E_{s, i, b} \quad$ non-heating (base) electricity load (kWh)

$O_{s, i, b} \quad$ binary indicator of active occupancy

3) Price/Temperature Profiles and Parameters

$\lambda_{i}^{-} \quad$ day-ahead electricity import price $(£ / \mathrm{kWh})^{1}$

$\lambda_{i}^{+} \quad$ day-ahead electricity export price $(£ / \mathrm{kWh})^{1}$

$\mu_{s, i}^{-} \quad$ imbalance electricity import price $(£ / \mathrm{kWh})^{1}$

$\mu_{s, i}^{+} \quad$ imbalance electricity export price $(£ / \mathrm{kWh})^{1}$

\footnotetext{
${ }^{1}$ Includes energy costs, network charges, and other relevant retail costs as applicable.
} 
$\gamma_{i} \quad$ gas price $(£ / \mathrm{kWh})$

$\varphi_{i}^{-} \quad$ penalty for deficient temperature $\left(£ /\left({ }^{\circ} \mathrm{C} \cdot \mathrm{h}\right)\right)$

$\varphi_{i}^{+} \quad$ penalty for excess temperature $\left(\mathfrak{f} /\left({ }^{\circ} \mathrm{C} \cdot \mathrm{h}\right)\right)$

$T_{s, i}^{\text {out }} \quad$ outside temperature $\left({ }^{\circ} \mathrm{C}\right)$

$p_{s} \quad$ scenario probability

4) Time-band Length

$l \quad$ length of time step (h)

\section{Variables}

$D_{i}^{-} \quad$ day-ahead energy import (kWh)

$D_{i}^{+} \quad$ day-ahead energy export $(\mathrm{kWh})$

$D_{i} \quad$ day-ahead energy $(\mathrm{kWh})$

$I_{s, i}^{-} \quad$ imbalance energy import $(\mathrm{kWh})$

$I_{s, i}^{+} \quad$ imbalance energy export $(\mathrm{kWh})$

$I_{s, i} \quad$ imbalance energy $(\mathrm{kWh})$

$H_{s, i, b} \quad$ heating electricity consumption (kWh)

$X_{s, i, b} \quad$ energy level of thermal energy store $(\mathrm{kWh})$

$T_{s, i, b} \quad$ internal temperature of dwelling $\left({ }^{\circ} \mathrm{C}\right)$

$T_{s, i, b}^{+} \quad$ temperature surplus $\left({ }^{\circ} \mathrm{C}\right)$

$T_{s, i, b}^{-} \quad$ temperature deficit $\left({ }^{\circ} \mathrm{C}\right)$

$L_{s, i, b}^{S H} \quad$ space heating load $(\mathrm{kWh})$

$G_{S, i} \quad$ gas consumption $(\mathrm{kWh})$

\section{INTRODUCTION}

$\mathrm{D}$ ISPATCHABLE generating assets have traditionally been the main source of flexibility in electricity systems. However, there is a need for incorporating new sources of flexibility in system operation [1], such as demand response (DR). DR is defined as any action on the demand side of the meter in response to price signals [2]. Any device which features some storage (of the end product or within a process) has the potential to provide flexibility for DR purposes [3]. Therefore of particular interest, for DR applications, are electro-thermal technologies (ETT). These include electric (resistive) heating, electric heat pumps (EHP) and combined heat and power (CHP). Such technologies have substantial thermal storage potential (in physical stores such as hot water TES or in dwelling materials exploiting embedded thermal inertia), and thus are a major source of potential flexibility.

The problem of optimization of storage-type customers under time-varying prices, in particular the complexity introduced by inter-temporal constraints, has long been recognized [4]. A key observation on this topic has been that benefits from operating storage are only realized if the price difference between storage charge and discharge periods exceeds losses associated with storage [3]. This observation drives the need to understand the physical basis of relevant storage resources and their associated losses and inertia. In this respect, with regards thermal modeling of dwellings, electrical analog models [5], which feature equivalent thermal resistances and capacitances, have been proposed as a suitable option. It should be noted that this option also provides the potential for linear optimization, as a model for the relevant decision-making process. For maximum scalability such models have been reduced to single-node lumpedsystem models [6]. With regards to modeling of TES, less work has been conducted (despite the developments that are making TES increasingly interesting [7]). Nevertheless, also for TES, there is a wide range of modeling approaches, from multi-nodal to single-node models [8]. However, it is notable that, in the current literature, a systematic unified model of both dwelling and TES, suitable to fully explore the benefit and interactions of such storage resources, does not exist. Moreover, when dealing with thermal storage based resources, technology specificity appears to be another limit. In fact, most of the current literature refers to a specific technology. This includes [3] and [7] pertaining to electric resistive heating, [4], [5] and [8]-[10] to air-conditioning for cooling, [12] to EHP for heating, and [13] to CHP for heating. However, limiting to one specific technology precludes the study of the complementarity of different ETT, such as EHP (consuming electricity when heat is needed) and CHP (producing electricity when heat is needed). This limitation also does not allow the study of relevant optimal portfolio analyses, considering the possibility of DR through day-ahead (DA) or real-time arbitrage among different energy vectors ${ }^{2}$ [14].

Besides shifting between energy vectors, thermal storage based resources may also offer DR from curtailment or shifting in time of the final energy service [15]. Exploitation of such flexibility necessitates the consideration of user preference [16] (equivalently comfort [17] or utility [18]). Such preference may be expressed as limits on service levels [16], [19]-[21], or through specification of the value of the energy service to be incorporated into a generalized cost objective function [6], [12], [22]-[24]. Focusing particularly on generalized cost approaches, [22] includes, in addition to monetary cost, costs related to waiting (for appliance operation). Similarly, [24] defines a transfer coefficient which can be conceived of as a measure of the willingness of the user to shift their appliance consumption in time. Another component of the objective can be a cost associated with thermal discomfort, as implemented in [6], [12], [23]. Outside of mathematical programming approaches, heuristic based methods have also been employed. In [17], for example, a demand aggregator seeks to deliver a given amount of demand reduction with minimal loss of user comfort, using genetic algorithms.

Following a level of service approach, flexibility in the heat stored in dwelling material may be exploited by allowing the temperature to vary within a certain deadband. However, this will result in the dwelling temperature usually, assuming a cost minimization objective, tending towards the lower bound [9]. To counter this effect, penalties on deviation of the temperature from the set temperature may be combined with the temperature bounds to enable a cost/comfort multiobjective optimization. These non-monetary penalties may be based on the predicted mean vote method, such as in [10], [25]. However, such measures are not completely generalizable as they are designed for measuring the comfort of large groups of people over extended periods of time [26]. A popular, more general, alternative approach is to explicitly place a price on deviations of the dwelling temperature from the set temperature (which may vary by dwelling and time). Such a price is often termed the "price of discomfort". This kind of approach is, for instance, followed in [6], [12], [23]. Notwith-

\footnotetext{
2 "energy vector" is synonymous with "energy carrier", denoting a substance that contains energy for use or conversion at a later stage
} 
standing the difficulty of determining an appropriate price for thermal discomfort, this approach may be considered practical. More specifically, in [6] a $\mathrm{mu} /\left({ }^{\circ} \mathrm{C}\right)^{2}$ coefficient is applied to the square of the deviation of the dwelling temperature from the set temperature for each dwelling class and time period. However, given that quantification of the price of discomfort may need to be clearly integrated into a contract between the party exploiting the flexibility (a "flexibility aggregator", such as an ESCo, or energy retailer) and the dwelling occupants, such a price coefficient may be inadequate. This is due to the failure to explicitly consider the duration of the deviation and therefore its comfort level impact, which will be crucial in specifying acceptable service levels in DR contracts. In [23], the price coefficient has unit $\mathrm{mu} /{ }^{\circ} \mathrm{C}$ which, although more intuitive than the unit $\mathrm{mu} /\left({ }^{\circ} \mathrm{C}\right)^{2}$ in [6], similarly does not explicitly consider the length of the deviation. In [12] these weaknesses are addressed though specification of the price of discomfort coefficient in the form $\mathrm{mu} /\left({ }^{\circ} \mathrm{C} \cdot \mathrm{h}\right)$. However, the application of this coefficient to the absolute value of the deviation precludes specification of different values for up/downward deviations. Also the approaches in [12], [23] preclude a price of discomfort which varies over time and across dwellings. Therefore, current approaches which consider the value of thermal comfort in exploitation of dwelling flexibility may be considered incomplete. Hence, such approaches may be unsuitable as a basis for specification of contracts between users and flexibility aggregators.

On the above premises, this work formally describes a comprehensive techno-economic model for aggregation of generic ETT with thermal storage (in the form of TES and/or dwelling material) for DR optimization, in a DA market context, with consideration of thermal comfort. The proposed model incorporates ETT and storage with dynamical equations, so as to allow linear optimization. Given the high degree of uncertainty inherent in the operation of ETT (primarily dictated by thermal requirements, as well as in market prices), a two-stage stochastic programming approach is employed [27]. This represents a simplification of the most comprehensive approach, a multi-stage framework. Under the assumption that uncertain parameters change relatively little during the considered period, the two-stage approach can be considered to provide a good estimate of the result of a full multi-stage problem. Additionally, the two-stage approach may be considered more practical given the complexity of a multi-stage approach. The stochastic programming approach includes consideration of the effect of uncertainty in outdoor temperature (a major determinant of space heating load), DHW load, base electricity load, occupancy and imbalance prices. This provides a full consideration of uncertainty affecting DR from ETT. Optimization is undertaken by a balancing responsible party fulfilling both a retailer (for inflexible base electricity demand) and ESCo role (providing thermal comfort and DHW to dwelling occupants).

Thermal discomfort is quantified using a new expected thermal discomfort (ETD) metric. The ETD metric is intended as a standard metric focused on the loss of energy service, rather than energy itself. Through application of a price of discomfort, such a metric can, as will be demonstrated, be incorporated into an ESCo optimization to produce more efficient results than alternative methods for exploiting flexibility. Further, the ETD can serve as a standard basis for determining user compensation for lost comfort, via the expected thermal discomfort cost (ETDC) measure, in DR contracts. This represents a different direction for specification of remuneration for space conditioning related DR contracts. Such contracts, in the past, have largely been specified based on available electrical power [28], [29], with no explicit appreciation of lost thermal comfort.

Following initial modeling carried out in [30], the formalization of a linear, non-technology specific unified stochastic programming model of both dwelling and TES, which enables appreciation of the complementarity of electricity consuming and generating ETT, is the major novel contribution of this paper. The consideration of all available storage (as opposed to previous limited approaches [6]-[8], [31]), in a stochastic fashion, considering the complexity of multiple scenarios and of inter-temporal constraints dictated by storage operation, is also a significant contribution. A further contribution lies in the explicit consideration of occupant thermal discomfort, via the ETD metric, for more efficient exploitation of flexibility and determination of compensation for lost comfort in DR contracts.

The remainder of the paper is organized as follows. Section II details the optimization problem formulation. Section III introduces and details case studies, showing the application of the formulation to a residential scenario with indwelling heating units and TES. Section IV provides the concluding remarks and bridges to future work.

\section{PROBLEM DESCRIPTION}

The problem described is that of a balancing responsible retailer-ESCo. The retailer-ESCo retails electricity for fulfilment of base electricity demand, while exercising direct control over ETT and TES to provide thermal comfort to contracted standards. In this work the contract between the dwelling occupants and the retailer-ESCo specifies a deadband (which may in case be zero) at times of active occupancy. Prices are specified for thermal discomfort (payable by the retailer-ESCo to the dwelling occupant, in the form of $f /\left({ }^{\circ} \mathrm{C} \cdot \mathrm{h}\right)$ ) for deviations below or above the limits of the specified deadband. Such an arrangement might be considered contentious given the necessity of sharing potentially sensitive data on building energy usage between the dwelling occupants and the actor fulfilling the retailer-ESCo role [32]. However, given the growing importance for society of $\mathrm{CO}_{2}$ reduction (which in turn motivates reduction in energy consumption and hence interest in the ESCo model [33]) it can be expected that such concerns will be mitigated appropriately. This will enable the retailer-ESCo access to the required information. Concerns may also be counteracted by the potential rewards available (in terms of $\mathrm{CO}_{2}$ reduction for society and bill reduction for the consumer).

Each dwelling has a thermal load (SH and DHW) and a (non-heat related) "base" electrical load, all subject to uncertainty. The retailer-ESCo's objective is to minimize the expected cost over the day considering DA market purchases, imbalance costs (additional cost for balancing its position which it might incur in real time due to demand forecast uncertainty), gas purchases, and payments to dwelling occu- 
pants for violation of contracted thermal comfort standards. Intra-aggregation balancing is assumed to be possible (e.g., in line with microgrid applications [34]), with import and export prices applied, to the aggregation's net import/export. The dwellings' thermal demand is served by an (electricity consuming or generating) ETT. The retailer-ESCo may create flexibility in each dwelling, to respond to uncertainty, through exploitation of a TES and/or through heat storage (thermal inertia) in building material. TES and dwellings are modeled as lumped systems [6], with one equivalent thermal resistance (modeling heat losses) and one thermal capacitance (modeling thermal inertia). Uncertainty in some problem parameters (see Section III.B) is modeled through use of scenarios, and the problem is cast as a two-stage stochastic optimization problem [35]. More specifically, decisions on DA purchases are made in the first (day-ahead) stage, while recourse decisions (ETT and TES set-points and imbalance settlement purchases) are made at the second stage (real time). Scenarios to model the relevant uncertainties can be formed with reference to parameter forecasts or through utilization of past records (or a combination of both). If past records are used, scenario reduction [35], [36] may be required to reduce the number of scenarios, in order to reduce model run-time to practical levels.

Energy prices include all relevant additional costs (such as network charges). In this respect, the formulation allows for separate directional (import and export) DA and imbalance prices. This is done so that some of these additional costs can be applied differently to import and export prices and in order to accommodate double and single pricing arrangements for imbalance prices.

\section{A. Retailer-ESCo's Objective Function}

The retailer-ESCo's objective (1) is to minimize its overall expected (day ahead and imbalance) electricity and gas costs over the day while maintaining contracted levels of thermal comfort (violations of which are penalized). Relevant uncertainties are considered. These are modeled through $N_{S}$ scenarios, each with probability of occurrence $p_{s}$.

$$
\operatorname{Min}\left\{\sum _ { i = 0 } ^ { N _ { i - 1 } } \left[\lambda_{i}^{-} D_{i}^{-}-\lambda_{i}^{+} D_{i}^{+}+\sum_{s=1}^{N_{s}} p_{s}\left(\mu_{s, i}^{-} I_{s, i}^{-}-\mu_{s, i}^{+} I_{s, i}^{+}+\right.\right.\right.
$$$$
\left.\left.\left.\gamma_{i} G_{s, i}+\sum_{b=1}^{N_{b}} O_{s, i, b}\left(\varphi_{i}^{+} T_{s, i, b}^{+}+\varphi_{i}^{-} T_{s, i, b}^{-}\right)\right)\right]\right\}
$$

\section{B. ETT/TES Modeling}

A key feature of the proposed formulation is the conceptualization of the ETT/storage resource. In this formulation the thermal load $\left(L_{s, i, b}^{S H}+L_{s, i, b}^{D H W}\right)$ is always non-negative, but the accompanying ETT electricity variable $H_{s, i, b}$ will be either non-negative (for electricity consuming ETT) or non-positive (for electricity generating ETT) for each dwelling, depending on the technology type. Hence, an electricity consuming ETT and electricity generating ETT can be modeled in the same way, differentiated only by the ratio of the thermal output to the electrical input $\rho_{s, i, b} \cdot \rho_{s, i, b}$ will take a positive value for an electricity consuming ETT (e.g., an EHP) and a negative one for an electricity generating ETT (e.g., a CHP).

Limits on the operating range of each ETT are described in (2) and (3). $P_{b}^{\min }$ and $P_{b}^{\max }$ are the electrical consumption power limits of the technology, which are transformed into heat energy limits by the application of $\rho_{s, i, b}$ and the time step duration $l$. Since $H_{s, i, b}$ and $\rho_{s, i, b}$ may be non-negative or non-positive, the formulation of (2) avoids the need for technology specific constraints ${ }^{3}$ :

$$
\rho_{s, i, b} P_{b}^{\min } l \leq \rho_{s, i, b} H_{s, i, b} \leq \rho_{s, i, b} P_{b}^{\max } l
$$

For all $s=1$ to $N_{s}, 0=1$ to $N_{i}, b=1$ to $N_{b}$.

In line with most heating system arrangements, heat passes from the ETT to the TES and then to the dwelling/DHW loads. Heat input from the ETT is specified by the second term on the right hand side of (3), followed by terms for inadvertent loss ${ }^{4}$ and $\mathrm{SH}$ and DHW loads. Constraint (4) limits the $\mathrm{SH}$ load to non-negative values:

$$
\begin{gathered}
X_{s, i+1, b}=X_{s, i, b}+\rho_{s, i, b} H_{s, i, b}-X_{s, i, b} l\left(R_{b}^{x} C_{b}^{x}\right)^{-1}-L_{s, i, b}^{S H} \\
-L_{s, i, b}^{D H W}
\end{gathered}
$$

For all $s=1$ to $N_{s}, i=0$ to $N_{i-1}, b=1$ to $N_{b}$.

$$
L_{s, i, b}^{S H} \geq 0
$$

For all $s=1$ to $N_{s}, i=0$ to $N_{i}, b=1$ to $N_{b}$.

Energy content limits of the TES energy level variable, $X_{s, i, b}$, are related to the minimum/maximum TES temperature, as described in (5).

$$
\left(X_{b}^{\min }-T_{s, i, b}\right) C_{b}^{x} \leq X_{s, i, b} \leq\left(X_{b}^{\max }-T_{s, i, b}\right) C_{b}^{x}
$$

For all $s=1$ to $N_{s}, i=0$ to $N_{i}, b=1$ to $N_{b}$.

The dwelling system is modeled in (6). The state of the dwelling is determined by its temperature $T_{s, i, b}$. The heat loss is described via the indoor-outdoor temperature differential and the dwelling resistance value:

$$
\begin{aligned}
T_{s, i+1, b}=T_{s, i, b}+ & \left(L_{s, i, b}^{S H}-\left(T_{s, i, b}-T_{s, i}^{\text {out }}\right) l\left(R_{b}\right)^{-1}\right. \\
& \left.+X_{s, i, b} l\left(R_{b}^{x} C_{b}^{x}\right)^{-1}\right)\left(C_{b}\right)^{-1}
\end{aligned}
$$

For all $s=1$ to $N_{s}, i=0$ to $N_{i-1}, b=1$ to $N_{b}$.

The limits on a dwelling's state (temperature) are described in (7). The basis of the limits is the set temperature of the dwelling $T_{s, i, b}^{s e t}$. As the set temperature is only required when the dwelling is occupied, the binary parameter $O_{s, i, b}$ is used to switch the constraint off when the dwelling is unoccupied. Without loss of generality $\delta_{i, b}^{\text {low }}$ and $\delta_{i, b}^{\text {high }}$ define the deadband around the set temperature, which may also be conceived of as limits on the storage capability of the dwelling, and therefore a measure of its flexibility. $T_{s, i, b}^{+}$and $T_{s, i, b}^{-}$ define the surplus and deficit temperature respectively, which are penalized, as appropriate, in the problem objective (1).

$$
\begin{gathered}
O_{s, i, b}\left(T_{i, b}^{s e t}-\delta_{i, b}^{l o w}\right) \leq O_{s, i, b}\left(T_{s, i, b}-T_{s, i, b}^{+}+T_{s, i, b}^{-}\right) \leq \\
O_{s, i, b}\left(T_{i, b}^{s e t}+\delta_{i, b}^{\text {high }}\right) \\
T_{s, i, b}^{-}, T_{s, i, b}^{+} \geq 0
\end{gathered}
$$

For all $s=1$ to $N_{s}, i=0$ to $N_{i}, b=1$ to $N_{b}$.

Equalities (9) and (10) set the initial (at time step 1, also equal to the first time step of the next day) and final states of the dwelling temperature and TES energy variables to be equal. Such constraints are necessary so that results are not

\footnotetext{
${ }^{3}$ Note that $P_{b}^{\min }, P_{b}^{\max }$ and $\rho_{s, i, b}$ take non-negative values for electricity consuming devices, and non-positive values for electricity producing devices (producing non-negative/non-positive values for heating electricity consumption $H_{s, i, b}$, respectively).

${ }^{4}$ As the TES energy content is measured relative to the dwelling temperature, the full loss term can be simplified as $\left(\left(X_{s, i, b}\left(C_{b}^{x}\right)^{-1}+T_{s, i, b}\right)-\right.$ $\left.T_{s, i, b}\right) l\left(R_{b}^{x}\right)^{-1}=X_{s, i, b} l\left(R_{b}^{x} C_{b}^{x}\right)^{-1}$.
} 
distorted through the setting of high temperatures at the start of the scheduling period and/or low temperatures at the end of the scheduling period.

$$
\begin{aligned}
& T_{s, 0, b}=T_{s, N_{i}, b} \\
& X_{s, 0, b}=X_{s, N_{i}, b}
\end{aligned}
$$

For all $s=1$ to $N_{s}, b=1$ to $N_{b}$.

\section{Energy Balance and Market Trading Constraints}

Equation (11) balances economic and physical electricity variables considering flexible ETT and inflexible (base) electricity consumption:

$$
D_{i}+I_{s, i}=\sum_{b=1}^{N_{b}}\left(H_{s, i, b}+E_{s, i, b}\right)
$$

For all $s=1$ to $N_{s}, i=0$ to $N_{i}$.

Key to note is that it is the net physical consumption/generation of the aggregation that is considered in (11). This implicitly allows the aggregation to self-serve electricity load, where possible. This may be especially attractive given a difference in import/export prices which will motivate arbitrage across time periods to increase self-consumption and reduce grid import.

Constraint (12) sets the DA import and export energy values to be non-negative, while (13) sets the net DA energy purchase equal to the DA import and export purchases. Constraint (14) sets the imbalance import/export energy values to be non-negative, while (15) sets the net imbalance energy purchase equal to the imbalance import and export purchases.

$$
\begin{gathered}
D_{i}^{-}, D_{i}^{+} \geq 0 \\
D_{i}^{-}-D_{i}^{+}=D_{i} \\
I_{s, i}^{-} I_{s, i}^{+} \geq 0 \\
I_{s, i}^{-}-I_{s, i}^{+}=I_{s, i}
\end{gathered}
$$

For all $s=1$ to $N_{s}, i=0$ to $N_{i}$.

In order to account for gas consumption by gas powered electricity generating ETT (e.g., CHP), (16) calculates gas usage of the aggregation as derived from the ratio of the electrical output $H_{s, i, b}$ to the electrical efficiency $\eta_{b}$ (assumed constant with different operation levels). The constraint is applied only to electricity generating ETT by means of the binary technology indicator $\left(\tau_{b}\right)$.

$$
G_{s, i}=-\sum_{b=1}^{N_{b}}\left(1-\tau_{b}\right) H_{s, i, b} \eta_{b}^{-1}
$$

For all $s=1$ to $N_{s}, i=0$ to $N_{i}$.

\section{CASE STUDY APPLICATIONS}

Several case study applications, involving an aggregation of fifty ${ }^{5}$ well-insulated residential flat dwellings, are considered. The retailer-ESCo procures (and, in case, sells) wholesale electricity at market prices, considering participation in the DA wholesale market. Non-energy costs (e.g., network charges, metering costs, customer services, taxes) are added to the import price of electricity. For comparison purposes, a 'No storage' test is defined. The results for each aggregation case (i.e., ETT selection) in the 'No storage' test are compared to a gas boiler load following case, to demonstrate comparison with the common present situation. The analysis will then consider several tests on the effect of utilizing TES

\footnotetext{
${ }^{5}$ In this case study, due to the saturation of benefits from diversity, there are insignificant marginal gains from increasing the aggregation size further.
}

and dwelling storage potential to minimize expected operational costs. According to the considered test, thermal storage is exploited through either a) specifying a deadband around the set temperature (up/down or up only), with no price/penalty for deviations from the set temperature within this deadband, and a $£ 1000 /\left({ }^{\circ} \mathrm{C} \cdot \mathrm{h}\right)$ penalty for deviations outside this deadband; or b) specifying a price of thermal discomfort $\left(£ /\left({ }^{\circ} \mathrm{C} \cdot \mathrm{h}\right)\right)$, set to be the same for upward and downward deviation from the set-point for these case studies, which is applicable to any deviation from the set temperature. The resultant ETDC is payable by the retailer-ESCo to the occupants, as part of the DR contract. Results are presented firstly considering only the expected energy costs. Subsequently expected thermal discomfort costs are presented. Analysis is undertaken for typical shoulder (spring/autumn, March-May and September-November), winter (DecemberFebruary) and summer (June-August) days, which are used to calculate the annual expected costs. The five aggregation cases considered are shown in Table I. The fourteen storage tests, plus the 'No storage' test, are shown in Table II. Flexibility parameters in the tests are arbitrary (the possibilities in reality are many, likely to vary widely between dwellings and poorly understood), but serve to usefully demonstrate the comparative results from the different approaches and sensitivity to the flexibility parameters. For exhaustive consideration, further investigation (including determination of flexibility parameters) would be required. All tests are repeated four times with different occupancy, base electricity, DHW and building parameters, so as to nullify any bias related to parameter selection. Time step length is set to 30 minutes

\begin{tabular}{|c|c|c|c|}
\hline & & No TES & 300 litre TES \\
\hline & No storage & 0 & \\
\hline \multirow{4}{*}{$\begin{array}{l}\text { Deadband } \\
\text { around set } \\
\text { temperature }\end{array}$} & $+/-2^{\circ} \mathrm{C}$ & 1 & 8 \\
\hline & $+/-1^{\circ} \mathrm{C}$ & 2 & 9 \\
\hline & $+2^{\circ} \mathrm{C}$ & 3 & 10 \\
\hline & $+1^{\circ} \mathrm{C}$ & 4 & 11 \\
\hline \multirow{3}{*}{$\begin{array}{c}\text { Price of } \\
\text { thermal } \\
\text { discomfort }\end{array}$} & $f 1 /\left({ }^{\circ} \mathrm{C} \cdot \mathrm{h}\right)$ & 5 & 12 \\
\hline & $£ 0.5 /\left({ }^{\circ} \mathrm{C} \cdot \mathrm{h}\right)$ & 6 & 13 \\
\hline & $\mathrm{f0.1} /\left({ }^{\circ} \mathrm{C} \cdot \mathrm{h}\right)$ & 7 & 14 \\
\hline
\end{tabular}
(corresponding to the length of the UK trading period), producing 48 time steps for each day modeled.

TABLE I

AGGREGATION CASES

\begin{tabular}{|c|c|}
\hline Aggregation case & Description \\
\hline 1 & Stirling engine CHP (SE) \\
\hline 2 & Air source heat pump (ASHP) \\
\hline 3 & SE/ASHP (equal mix) \\
\hline 4 & Internal combustion engine CHP (ICE) \\
\hline 5 & ICE/ASHP (equal mix) \\
\hline
\end{tabular}

TABLE II

DESCRIPTIONS OF THE TESTS, WITH ASSOCIATED TEST NUMBER

\section{A. Resource Parameter Synthesis}

Each resource is composed of three parts: the ETT, the dwelling, and, in case, the TES. ETT are defined by their operating limits $\left(P_{b}^{\max }\right.$ and $\left.P_{b}^{\min }\right)$ and performance parameters $\left(\rho_{s, i, b}\right.$ and $\left.\eta_{b}\right) . P_{b}^{\max }$ is set such that the ETT is able to heat the dwelling during design conditions (assumed here $T_{s, i}^{\text {out }}=-4^{\circ} \mathrm{C}$ and $T_{s, i, b}=21^{\circ} \mathrm{C}$ for all $s=1$ to $N_{s}, i=0$ to $N_{i}$ and $b=1$ to $N_{b}$ ) while supplying the maximum possible DHW demand. $P_{b}^{\min }$ is set to 0 for all $b=1$ to $N_{b}$. For ASHPs the 
performance parameters are taken from the brochure of a commercially available model [37]. COP values are given for $0^{\circ} \mathrm{C}(1.97)$ and $20^{\circ} \mathrm{C}$ (3.51). From these values a linear COP/outdoor temperature function is derived. For SE units $\eta_{b}=0.13$ and $\rho_{s, i, b}=-6$ for all $s=1$ to $N_{s}, i=0$ to $N_{i}$ and $b=1$ to $N_{b}$ (thermal/electrical efficiency of $78 \% / 13 \%$ ). For ICE units $\eta_{b}=0.24$ and $\rho_{s, i, b}=-2.83$ for all $s=1$ to $N_{s}, i=0$ to $N_{i}$ and $b=1$ to $N_{b}$ (thermal/electrical efficiency $68 \% / 24 \%$ ).

Each dwelling is defined by a series of set-point controls and operating limits, and by dwelling characteristics, which are consistent across all tests. The set-temperatures $T_{i, b}^{s e t}$ are set according to a pseudo-random process based on the distribution of observed set-temperatures [38]. The dwelling operating limits are defined by $\delta_{i, b}^{\text {low }}$ and $\delta_{i, b}^{\text {high }}$, which are both set equal to 0 for all $i=0$ to $N_{i}$ and $b=1$ to $N_{b}$ as a default. The dwelling characteristics $\left(R_{b}^{b}\right.$ and $\left.C_{b}^{b}\right)$ are derived as in [30].

The TES are defined by their operating limits and characteristic parameters. The operating limits $\left(X_{b}^{\max }\right.$ and $\left.X_{b}^{\min }\right)$ vary with the ETT unit used. Upper (lower) limits are $80^{\circ} \mathrm{C}$ $\left(55^{\circ} \mathrm{C}\right)$ for CHP units and $55^{\circ} \mathrm{C}\left(40^{\circ} \mathrm{C}\right)$ for an ASHP for all $b$ $=1$ to $N_{b}$. The characteristic parameters of the TES ( $R_{b}^{x}$ and $C_{b}^{x}$ ) are derived from a brochure for a commercially available range of heat stores [39] $\left(R_{b}^{x}=568{ }^{\circ} \mathrm{C} / \mathrm{kW}, \quad C_{b}^{x}=\right.$ $0.3483 \mathrm{kWh} /{ }^{\circ} \mathrm{C}$ for all $b=1$ to $N_{b}$ ). For all tests the same resource parameters are used so that results are comparable across tests.

\section{B. Scenario Formulation}

At the DA stage, uncertainty exists in several sets of parameters, namely: DHW load, active occupancy, and outside temperature (determinants of demand for heat); base electricity load (which affects the aggregation diversity and the market for generated electricity); and imbalance prices for deviations from the DA position. Of particular note is the uncertainty in outside temperature and imbalance prices given the coincidence of such parameters across the aggregation. Any party utilizing an approach such as described here would undoubtedly develop bespoke methods utilizing extensive historical information. For the purposes of this work scenarios are formulated as described below.

\section{1) Temperature Profile Scenario Formulation}

For this work three outdoor temperature scenarios were formed using synthesized forecasts and information on forecast accuracy. A central scenario is set to the forecast (emulated by selecting a representative temperature profile from past records). High/low scenarios are set by constructing a probability density function (PDF) for the actual-forecast temperature deviation variable, using data on the day ahead forecast accuracy statistics [40], and assuming a normal distribution. The temperature profile for the high/low scenarios are then set according to the derived PDF, given probability $0.9 / 0.1$, respectively. The scenarios are then assigned user defined probabilities; 0.6 for the central forecast and 0.2 for the high and low forecasts. The utilized profiles for winter and shoulder seasons (heating not required in the summer season) are shown in Fig. 1.

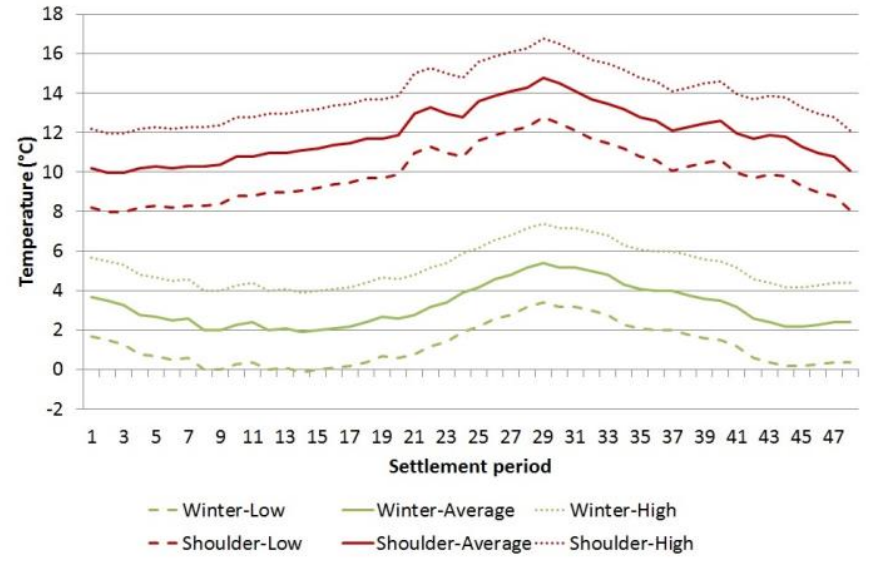

Fig. 1. Temperature scenarios.

\section{2) Price Profile Formulation}

Imbalance price scenarios are formed using past records (from the relevant season/day of week from UK data from the period 01/01/2009-31/07/2012) of imbalance price [41] (import/export) deviation from the DA (import/export) price [42]. A simultaneous backward reduction algorithm [43] is used to reduce the scenarios to find the ten most representative sets of imbalance price deviations for each season. These sets of deviations are then applied to the DA price to produce the imbalance price scenarios required for the optimization.Utlised price data is referenced online [44]. The ten imbalance price scenarios are combined with the three outdoor temperature scenarios to form thirty scenarios, in total. The gas price was taken as the prevailing retail gas price, $£ 0.038 / \mathrm{kWh}$.

\section{3) Consumer Energy/Active Occupancy Scenarios}

To adequately model the variability of consumer energy/occupancy profiles, a consistent set of base electricity, DHW, and active occupancy profiles for each dwelling is randomly assigned to each scenario. Dwelling active occupancy $\left(O_{s, i, b}\right)$ and base electricity demand $\left(E_{s, i, b}\right)$ are synthesized utilizing the residential electricity model found in [45]. The accompanying DHW demand $\left(L_{s, i, b}^{D H W}\right)$ profile is synthesized using a bespoke tool, as described in [46].

\section{Results}

The first set of results compare expected energy and discomfort costs for the 'No storage' test, for the various aggregation cases, to a gas boiler load following case (i.e., the standard technology and control policy currently employed in the UK). In the load following case heating is operated when there is an active occupant to maintain the target temperature (a simplification on the usual hysteresis approach, maintaining temperature between two points rather than at one specific temperature). This enables the advantages of the proposed cases over the current situation to be understood. Secondly results are presented for the storage tests, considering expected energy and discomfort costs.

\section{1) 'No Storage' Tests}

Fig. 2 shows the expected energy costs for each case for the 'No storage' test. The greatest expected energy cost savings, compared to the gas boiler/load following case, are in the CHP (ICE and SE) cases. Although the relative perfor- 
mance of the given heating technologies is the primary factor in the cost savings, the application of non-energy costs to imported energy but not exported energy, which rewards selfconsumption of electricity, also contributes. An important point of note is that the ASHP/CHP case studies are not directly comparable to the gas boiler case. This is because in the ASHP/CHP cases thermal comfort is guaranteed (see (7)), while there is no such guarantee in the gas boiler load following case. For complete comparison of the cases presented in Fig. 2, the ETD metric is required. The ETD metric measures the expected difference between required and delivered thermal comfort, i.e., the deviation of the indoor temperature from the set-point, integrated over time. For the gas boiler case in Fig. 2 the ETD is $5957^{\circ} \mathrm{C} \cdot \mathrm{h} /$ year, while in the other presented cases, it is $0^{\circ} \mathrm{C} \cdot \mathrm{h} /$ year.

\section{2) Storage Tests-Expected Energy Cost}

Fig. 3 and Fig. 4 show the results, in terms of expected energy cost for the No TES tests (tests 1-7) and 300 liter TES tests (tests 8-14) respectively. The tests based on definition of a non-zero deadband consistently produce lower expected energy costs than the price of discomfort cases. Both with and without presence of a TES, expected energy costs are least for all aggregation types in the $+/-2^{\circ} \mathrm{C}$ tests followed by the $+/-1^{\circ} \mathrm{C}$ tests. Expected energy costs are similar, with and without TES, in the $+2{ }^{\circ} \mathrm{C}$ and $+1{ }^{\circ} \mathrm{C}$ tests. This is due to the dwelling thermal conductance being such that storing more than $1{ }^{\circ} \mathrm{C}$ of heat in the dwelling material is economically inefficient (for the given case). For the price of discomfort tests, expected energy costs are correlated with the price of discomfort, as lower prices enable more comfort to be traded for energy. Notable, however, is the relatively insignificant difference in expected energy costs for the three price of discomfort tests, given presence of a TES (see Fig. 4), as opposed to notable differences in the No TES tests. This is because the potential value from deployment of storage is limited so that the marginal reduction in expected energy costs decreases with every additional 'unit' of storage.

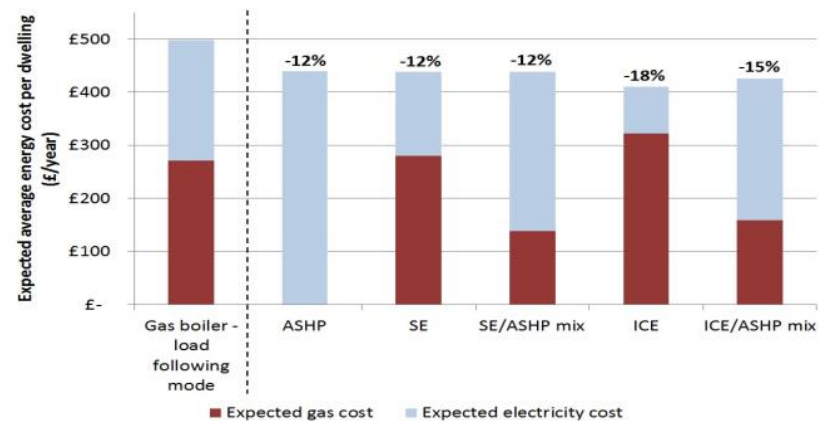

Fig. 2. Expected energy costs and cost savings on the gas boiler case per dwelling, no storage.

While, in the tests demonstrated, the full potential energy cost reduction is not achieved, the marginal reduction does become nearly insignificant. Also of note are the lower expected energy costs in the No TES tests compared to the TES tests for some aggregations involving CHP plant. This is due to the tension between the value brought by the flexibility of TES and the extra cost associated with the TES heat loss, which is greater for TES attached to CHP plant, given the higher temperature of heat storage. This effect is most marked for cases which assign low price of thermal discomfort (including tests 1-4 and 8-11), as the flexibility of the TES has higher potential value in the tests with higher price of thermal discomfort. This means that the value produced by the addition of the TES outweighs costs associated with the attendant heat loss.

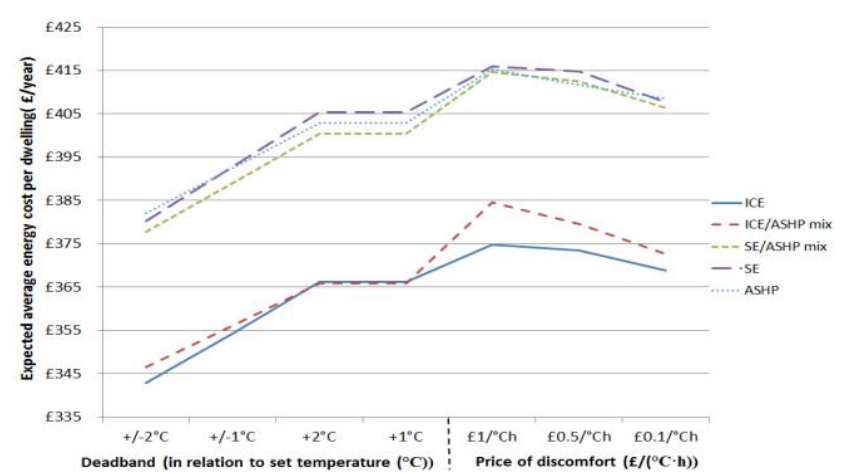

Fig. 3. Expected energy cost in the No TES tests (1-7) by aggregation type.

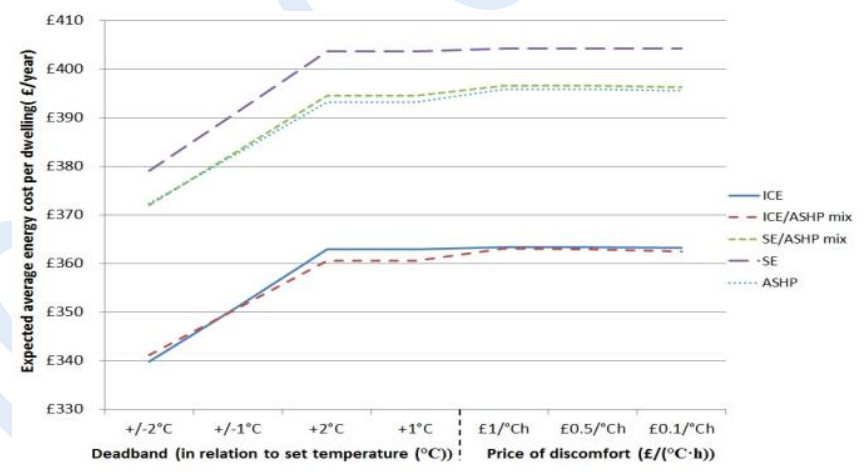

Fig. 4. Expected energy cost in the 300 liter TES tests (8-14) by aggregation type.

\section{3) Storage Tests- Expected Discomfort Cost}

For tests 5-7 and 12-14 the ETDC is shown in Table III. Notable is the clear difference between the No TES and TES tests. This is a consequence of the previously highlighted limited total available benefit of storage. Such information may be useful in any business case assessment for TES deployment, as the business case for any TES deployment clearly may vary dependent on the price of discomfort of the dwelling occupants.

TABLE III

ANNUAL AVERAGE ETDC PER DWELLING FOR PRICE OF DISCOMFORT TESTS,

\begin{tabular}{|c|c|c|c|c|c|c|}
\hline & \multicolumn{3}{c|}{ No TES } & \multicolumn{3}{c|}{$\mathbf{3 0 0}$ litre TES } \\
\hline Price $f /\left({ }^{\circ} \mathrm{C} \cdot \mathrm{h}\right)$ & $£ \mathbf{f 1}$ & $\mathbf{f 0 . 5}$ & $\mathbf{f 0 . 1}$ & $\mathbf{£ 1}$ & $\mathbf{f 0 . 5}$ & $\mathbf{f 0 . 1}$ \\
\hline ICE & $£ 0$ & $£ 1$ & $£ 2$ & $£ 0$ & $£ 0$ & $£ 0$ \\
\hline ICE/ASHP mix & $£ 2$ & $£ 4$ & $£ 4$ & $£ 0$ & $£ 0$ & $£ 0$ \\
\hline SE/ASHP mix & $£ 1$ & $£ 2$ & $£ 4$ & $£ 0$ & $£ 0$ & $£ 0$ \\
\hline SE & $£ 0$ & $£ 1$ & $£ 4$ & $£ 0$ & $£ 0$ & $£ 0$ \\
\hline ASHP & $£ 2$ & $£ 4$ & $£ 2$ & $£ 0$ & $£ 0$ & $£ 0$ \\
\hline
\end{tabular}

Although no price of discomfort is specified in the deadband tests (and hence there is no payment from the retailerESCo to the occupants for any deviation from the set-point) it 
is instructive to consider the possible value of lost comfort to the occupant. In this case, the ETDC may be considered a measure of the un-monetized transfer of benefits from the occupants to the retailer-ESCo. Fig. 5 shows these results for the No TES test, given various values for the price of discomfort (the results of the equivalent TES tests (8-11) is omitted here given their indiscernible similarity at the given scale). In the most extreme case (for an ICE aggregation test 8 with a price of discomfort of $£ 1$ and test 12) adoption of the price of discomfort approach (total expected costs £385) over the deadband approach (costs and disbenefits of £6509) reduces the total costs/disbenefits by $94 \%$.

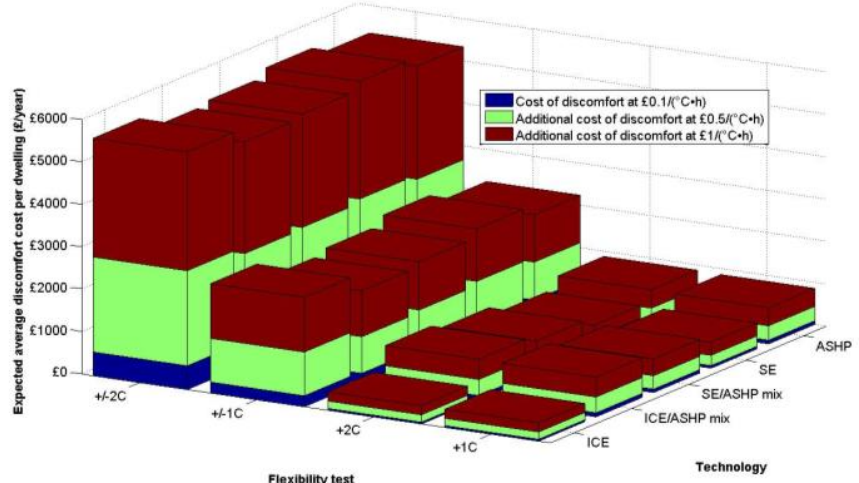

Fig. 5. Expected cost of energy and discomfort for the No TES tests (tests $1-4)$, by aggregation type.

\section{CONCLUSION}

This paper presents a physically based model which is applicable to both electricity consuming and electricity generating ETT. The model physically characterizes the main elements of storage associated with ETT, namely a TES and the dwelling material. This enables assessment of the ability of such resources to optimize operation through utilization of the flexibility from the available storage potential. Explicit consideration is given to thermal comfort of dwelling occupants through the introduced ETD metric. Market participation is modeled through DA market trading with imbalance responsibility. The problem is formulated as a two-stage stochastic problem.

The presented case study, of a retailer-ESCo optimizing various cases (varying by ETT and flexibility) of a portfolio of 50 residential flats, illustrates how the presented model can determine the expected energy and discomfort costs for a variety of cases. The power of the model lies in the ability to identify and quantify specific effects of a given case. Particular findings of note include: the substantial cost reduction resulting from the introduction of an optimized ETT, which is achieved despite the accompanying decrease in ETD; the decreasing marginal benefit of increasing flexibility, suggesting a saturation point for flexibility benefits; tension between operational benefits and costs from inclusion of a TES, as thermal losses from heat storage at high temperature weigh down on benefits; the superior efficiency (in terms of retailerESCo costs and benefits) of exploiting flexibility through specification of a price for thermal discomfort; the limited sensitivity of ETDC to the presence of a TES, given employment of the thermal discomfort price approach, which is particularly relevant for TES business case appraisal; and the substantial transfer of benefits from dwelling occupants to a retailer-ESCo given employment of a deadband around the set temperature. It should be noted, however, that the numerical results demonstrated are case specific and should not be generalized.

Further development of the presented model includes integration into a tool for determination of contract terms for exploitation of flexibility through utilization of the ETD metric, reducing run-times by reducing complexity and general efficiency, and moving to a full multi-stage approach. Other markets, such as for ancillary services, may be investigated too.

\section{ACKNOWLEDGEMENT}

The authors thank the anonymous reviewers for their comprehensive and diligent comments, which have contributed significantly to improving the paper.

\section{REFERENCES}

[1] G. Strbac, D. Pudjianto, P. Djapic, and S. Gammons, "Understanding the Balancing Challenge," Imperial College London, London, UK, Aug. 2012.

[2] M. H. J. Bollen, The Smart Grid: Adapting the Power System to New Challenges, 1st ed. Morgan \& Claypool Publishers, 2011, p. 180.

[3] D. S. Kirschen, "Demand-Side View of Electricity Markets," IEEE Trans. Power Syst., vol. 18, no. 2, pp. 520-527, 2003.

[4] B. Daryanian, R. E. Bohn, and R. D. Tabors, "Optimal Demand-Side Response to Electricity Spot Prices for Storage-Type Customers," IEEE Power Eng. Rev., vol. 9, no. 8, pp. 36-36, Aug. 1989.

[5] A. Molina-García, A. Gabaldon, J. A. Fuentes, and C. Alvarez, "Implementation and assessment of physically based electrical load models: application to direct load control residential programmes," in IEE Proc. -Gen., Transm. and Distr., 2003, vol. 150, no. 1, p. 61.

[6] D. Menniti, F. Costanzo, N. Scordino, and N. Sorrentino, "PurchaseBidding Strategies of an Energy Coalition With Demand-Response Capabilities," IEEE Trans. Power Syst., vol. 24, no. 3, pp. 1241-1255, 2009.

[7] A. Arteconi, N. J. Hewitt, and F. Polonara, "State of the art of thermal storage for demand-side management," Appl. Energy, vol. 93, pp. 371-389, Jan. 2012.

[8] L. Paull, H. Li, and L. Chang, "A novel domestic electric water heater model for a multi-objective demand side management program," Electr. Power Syst. Res., vol. 80, no. 12, pp. 1446-1451, Dec. 2010.

[9] J. Cigler, S. Prívara, Z. Váňa, E. Žáčeková, and L. Ferkl, “Optimization of Predicted Mean Vote index within Model Predictive Control framework: Computationally tractable solution," Energy Build., vol. 52, pp. 39-49, Sep. 2012.

[10] R. Z. Freire, G. H. C. Oliveira, and N. Mendes, "Predictive controllers for thermal comfort optimization and energy savings," Energy Build., vol. 40, no. 7, pp. 1353-1365, Jan. 2008.

[11] N. Ruiz, I. Cobelo, and J. Oyarzabal, "A Direct Load Control Model for Virtual Power Plant Management," IEEE Trans. Power Syst., vol. 24, no. 2, pp. 959-966, 2009.

[12] T. S. Pedersen, P. Andersen, K. M. Nielsen, H. L. Starmose, and P. D. Pedersen, "Using heat pump energy storages in the power grid," in Control Applications (CCA), 2011 IEEE International Conference on, 2011, pp. 1106-1111.

[13] N. J. Kelly, J. A. Clarke, G. Burt, and A. Ferguson, "Developing and testing a generic micro-combined heat and power model for simulations of dwellings and highly distributed power systems," Proc. Inst. Mech. Eng. Part A J. Power Energy, vol. 222, no. 7, pp. 685-695, Nov. 2008.

[14] P. Mancarella and G. Chicco, "Real-Time Demand Response From Energy Shifting in Distributed Multi-Generation," IEEE Trans. Smart Grid, vol. 4, no. 4, pp. 1928-1938, 2013.

[15] P. Siano, "Demand response and smart grids-A survey," Renew. Sustain. Energy Rev., vol. 30, pp. 461-478, Feb. 2014.

[16] M. C. Bozchalui, S. A. Hashmi, H. Hassen, C. A. Cañizares, and K. Bhattacharyya, "Optimal Operation of Residential Energy Hubs in 
Smart Grids," IEEE Trans. Smart Grid, vol. 3, no. 4, pp. 1755-1766, 2012.

[17] Y. Shimomura, Y. Nemoto, F. Akasaka, R. Chiba, and K. Kimita, "A method for designing customer-oriented demand response aggregation service," CIRP Ann. - Manuf. Technol., vol. 63, no. 1, pp. 413-416, 2014.

[18] G. Koutitas, "Control of Flexible Smart Devices in the Smart Grid," IEEE Trans. Smart Grid, vol. 3, no. 3, pp. 1333-1343, Sep. 2012.

[19] M. A. A. Pedrasa, T. D. Spooner, and I. F. Macgill, "Coordinated Scheduling of Residential Distributed Energy Resources to Optimize Smart Home Energy Services," IEEE Trans. Smart Grid, vol. 1, no. 2, pp. 134-143, 2010.

[20] Z. Chen, L. Wu, and Y. Fu, "Real-Time Price-Based Demand Response Management for Residential Appliances via Stochastic Optimization and Robust Optimization," IEEE Trans. Smart Grid, vol. 3, no. 4, pp. 1822-1831, 2012.

[21] P. Du and N. Lu, "Appliance commitment for household load scheduling," IEEE Trans. Smart Grid, vol. 2, no. 2, pp. 411-419, May 2011.

[22] A.-H. Mohsenian-Rad and A. Leon-garcia, "Optimal Residential Load Control With Price Prediction in Real-Time Electricity Pricing Environments," IEEE Trans. Smart Grid, vol. 1, no. 2, pp. 120-133, 2010.

[23] D. T. Nguyen and L. B. Le, "Joint Optimization of Electric Vehicle and Home Energy Scheduling Considering User Comfort Preference," IEEE Trans. Smart Grid, vol. 5, no. 1, pp. 188-199, 2014.

[24] B. Liu and Q. Wei, "Home energy control algorithm research based on demand response programs and user comfort," in Proc. of 2nd Int. Conf. on Measurement, Information and Control, 2013, pp. 995-999.

[25] P. O. Fanger, "Thermal comfort. Analysis and applications in environmental engineering." Copenhagen, Danish Technical Press, 1970.

[26] M. Castilla, J. D. Álvarez, M. Berenguel, F. Rodríguez, J. L. Guzmán, and M. Pérez, "A comparison of thermal comfort predictive control strategies," Energy Build., vol. 43, no. 10, pp. 2737-2746, Oct. 2011.

[27] A. J. Conejo, M. Carrión, and J. M. Morales, Decision making under uncertainty. Springer, 2010, p. 542.

[28] P. Cappers, C. Goldman, and D. Kathan, "Demand response in U.S. electricity markets: Empirical evidence," Energy, vol. 35, no. 4, pp. 1526-1535, Apr. 2010.

[29] Federal Energy Regulatory Commission, "Assessment of Demand Response and Advanced Metering Staff Report," Washington, D.C.

[30] N. Good, A. Navarro-Espinosa, E. Karangelos, and P. Mancarella, "Participation of electric heat pump resources in electricity markets under uncertainty," in Proceedings of 10th International Conference on the European Energy Market, EEM 2013, 2013.

[31] M. D. Ilic, L. Xie, and J. Joo, "Efficient Coordination of Wind Power and Price-Responsive Demand - Part II: Case Studies," Trans. Power Syst., vol. 26, no. 4, pp. 1885-1893, 2011.

[32] P. McDaniel and S. W. Smith, "Security and Privacy Challenges in the Smart Grid," IEEE Secur. Priv., vol. 7, no. 3, pp. 75-77, 2009.

[33] M. J. Hannon, T. J. Foxon, and W. F. Gale, "The co-evolutionary relationship between Energy Service Companies and the UK energy system: Implications for a low-carbon transition," Energy Policy, vol. 61, pp. 1031-1045, Jul. 2013.

[34] C. Schwaegerl, L. Tao, P. Mancarella, and G. Strbac, "A multiobjective optimization approach for assessment of technical , commercial and environmental performance of microgrids," Eur. Trans. Electr. Power, vol. 21, pp. 1271-1290, 2011.

[35] J. M. Morales, S. Pineda, A. J. Conejo, and M. Carrión, "Scenario Reduction for Futures Market Trading in Electricity Markets," IEEE Trans. Power Syst., vol. 24, no. 2, pp. 878-888, 2009.

[36] J. Dupacova, N. Growe-Kuska, and W. Romisch, "Scenario reduction in stochastic programming An approach using probability metrics," Math. Program., vol. 95, pp. 493-511, 2003.

[37] Calorex, Maldon, Essex, UK, Domestic Heat Pumps. (2010) Available: http://www.calorex.com/heat-pumps-domestic/air-sourcedomestic-ashp

[38] M. Shipworth, S. Firth, M. Gentry, A. Wright, D. Shipworth, and K. Lomas, "Central heating thermostat settings and timing: building demographics," Build. Res. Inf., vol. 38, no. 1, pp. 50-69, Jan. 2010.

[39] Dimplex, Southampton, Hampshire, UK , Unvented Hot Water Cylinders. (2011) Available: http://www.dimplex.co.uk/products/ renewable solutions/accessories/Heat_Pump_Cylinders/index.htm.

[40] Met Office, "How accurate are our public forecasts?," 2012. [Online]. Available: http://www.metoffice.gov.uk/aboutus/who/accuracy/forecasts. Accessed on Oct. 15, 2012.
[41] Elexon, “SSP/SBP/NIV," 2014. [Online]. Available: www.elexonportal.co.uk/sspsbpniv. Accessed on Nov. 10, 2014.

[42] APX-ENDEX, “APX Power UK," 2014. [Online]. Available: https://www.apxgroup.com/market-results/apx-power-uk/ukpx-rpdhistorical-data/. Accessed on Nov. 10, 2014.

[43 H. Heitsch and W. Romisch, "Scenario Reduction Algorithms in Stochastic Programming," Comput. Optim. Appl., vol. 24, no. 2-3, pp. 187-206, 2003.

[44] N. Good, E. Karangelos, A. Navarro-Espinosa, and P. Mancarella, "TSG-00781-2014 price data,", 2015. [Online]. Available: http://goo.gl/zkAwpZ. Accessed on Jan. 31, 2015.

[45] I. Richardson, M. Thomson, D. Infield, and C. Clifford, "Domestic electricity use: A high-resolution energy demand model," Energy Build., vol. 42, no. 10, pp. 1878-1887, Oct. 2010.

[46] N. Good, L. Zhang, A. Navarro-Espinosa, and P. Mancarella, "High resolution modelling of multi-energy domestic demand profiles," Appl. Energy, vol. 137, pp. 193-210, Jan. 2015.

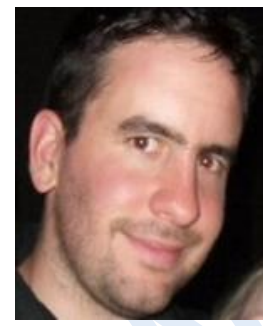

Nicholas Good (S'11) received the B.Sc (Hons) degree in mathematics, statistics and operational research from the University of Manchester, UK, in 2004 and the M.Sc degree in energy and the environment from Lancaster University, UK, in 2011. $\mathrm{He}$ is currently pursuing a Ph.D degree in electrical engineering from the University of Manchester. His research interests include multi-energy modelling and optimization of distributed energy resources and associated business case development.

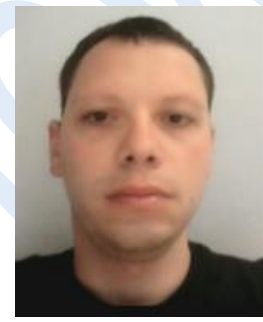

Efthymios Karangelos (M'13) received the Diploma in mechanical engineering from the National Technical University of Athens, Greece, in 2005, the M.Sc. degree in power systems engineering and economics in 2007, and the $\mathrm{PhD}$ degree in electrical engineering in 2012, both from the University of Manchester, UK, In 2012, he joined the department of electrical engineering and computer science of the University of Liège, Belgium, as a postdoctoral researcher. His research interests include power system modeling, reliability, economics and optimization.

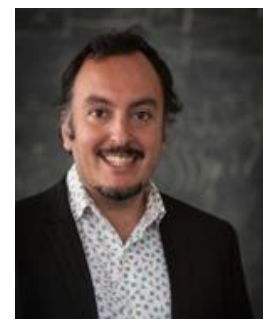

Alejandro Navarro-Espinosa (S'08) received the Industrial Engineer and M.Sc. degrees from the Pontificia Universidad Catolica (PUC) in Chile in 2004 and 2007, respectively. He also holds a M.Sc. in Power Systems from The University of Manchester, UK, in 2011. Currently, he is pursuing a $\mathrm{Ph} . \mathrm{D}$. in future low voltage distribution networks at The University of Manchester. Previously, he was Technical Chief Executive at Systep and lecturer at Universidad de los Andes, Chile.

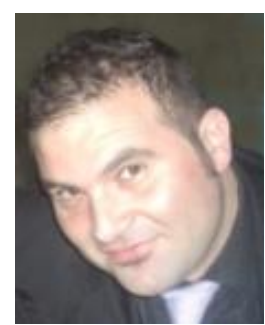

Pierluigi Mancarella (M'08, SM'14) received the Ph.D. degree in Power Systems from the Politecnico di Torino, Italy. After being a Research Associate at Imperial College London, he is currently a Reader in Future Energy Networks at the University of Manchester. His research interests include multi-energy systems modelling, business models for low carbon technologies, and network investment under uncertainty. 